\title{
RAMON LLULL, Raimundi Lulli Opera Latina XXXVIII (142-153) anno 1309 composita. A cargo de FERNANDO DOMÍNGUEZ REBOIRAS, Turnhout, Brepols (Corpus Christianorum Continuatio Mediaevalis 266), 2017, CXV + 364 pp., ISBN: 9782503557038
}

El libro que nos ocupa presenta una edición filológica, acompañada de estudios, comentarios y notas, de un conjunto de obras lulianas heterogéneo por su entidad y temática. En dicho conjunto, encontramos: a) el Liber de acquisitione Terrae Sanctae, un tratado de estrategia militar para convertir todo el Mediterráneo en un mare nostrum cristiano; b) cuatro cartas dirigidas por Llull a destacadas autoridades civiles y eclesiásticas de la época, en las que les pide ayuda para su proyecto de crear monasterios dedicados a la formación de misioneros en lenguas como el árabe, el tártaro o el griego; c) una serie de tratados de carácter filosófico-teológico, en los que Llull utiliza el razonamiento silogístico para tratar de probar racionalmente las verdades de la fe cristiana. Sin embargo, a pesar de la mencionada heterogeneidad temática, se aprecia en todas ellas, formulado mediante canales y medios de expresión diferentes, un mismo y claro objetivo proselitista: la voluntad de extender la cristiandad, sea por medio de las armas, sea por medio de argumentos lógicos y racionales (las rationes necessariae de las que habla en sus textos), a todos los confines del mundo conocido. Además, todas ellas excepción hecha de tres de las cartas editadas, de datación problemática- fueron redactadas entre el invierno y la primavera del año 1309 en Montpellier, verdadero centro de operaciones de Llull, en donde desarrolló una cantidad nada despreciable de su ingente producción escrita. La edición y estudio de los textos reunidos en el volumen ha sido llevada a cabo por el Dr. Fernando Domínguez Reboiras (Raimundus Lullus Institut, Universidad de Freiburg), uno de los mejores conocedores de la obra y el pensamiento lulianos.

\section{La «Introducción general»: contextualización histórica}

El volumen se abre con una extensa introducción en la que, de forma solvente y documentada, Domínguez sitúa las obras editadas en las coordenadas históricas en que fueron producidas y explica de qué modo encajan en la intensa actividad intelectual desarrollada por Llull durante ese mismo periodo. Como es sabido, tal actividad llevó al filósofo y polígrafo mallorquín, hombre dotado de una «visión (...) universal de los problemas políticos de su entorno» (p. XXXV), a exponer su pensamiento (en particular, sus ideas sobre el bien de la cristiandad y la conversión de los pueblos no cristianos) ante algunos de los hombres más poderosos e influyentes de la Europa de finales del siglo XIII y principios del XIV, como, por ejemplo, el papa Clemente V o los reyes Felipe IV de Francia y Jaime II de Aragón. El investigador dedica un espacio generoso a analizar los contactos trabados por Llull con estos destacados actores de la política internacional del momento, y muestra hasta qué punto dichos contactos explican directa o indirectamente la génesis de algunos de los tratados recogidos en el libro. Así, al tratar la cordial relación que hasta el final de sus días mantuvo Llull con el rey de Aragón, ubica el origen de esta hacia las postrimerías del año 1299 (p. XXXII), cuando el beato pasó cerca de tres meses en Barcelona. Durante la estancia de Llull en esta ciudad, en efecto solicitó y obtuvo del monarca una licencia para poder predicar en mezquitas y sinagogas de todos los territorios vinculados a la Corona de Aragón. Domínguez destaca el hecho de que Llull solicitara este permiso al rey aragonés, y no al de Mallorca, del que era súbdito natural, y especula sobre las causas que pudieron llevarle a decantarse por la primera opción, entre las que destaca tres, a saber: a) el convencimiento de que los mallorquines no estarían interesados en la conversión de los musulmanes, pues obtenían grandes beneficios del comercio de esclavos; b) el sentido práctico de Llull, que le hacía percatarse de que una licencia concedida por el rey de Aragón resultaba válida para todos los dominios de la Corona de Aragón, incluidos los del reino vasallo de Mallorca, mientras que no sucedía lo mismo si la licencia la expedía el rey mallorquín; c) un posible distanciamiento de Llull con Jaime II de Mallorca (pp. XXXIV-XV). Por otro lado, Domínguez resume muy bien los principales ejes de la ambiciosa política mediterránea desplegada por el rey de Aragón durante la primera década del siglo XIV (pp. XXXIXLXXIII), particularmente los concernientes a sus movimientos diplomáticos para conseguir la implicación del papado y Castilla en una gran expedición contra Granada, y muestra los puntos de contacto existentes entre los planes cruzados del soberano aragonés y la visión luliana de un bellum perpetuum contra los infieles como un esfuerzo conjunto de los cristianos que, empezando por el sur de España, prosiguiera por las costas del norte de 
África en dirección hacia Tierra Santa. En este sentido, el investigador no considera un hecho casual que una obra como el Liber de acquisitione Terrae Sanctae (op. 146), fuera concluido en marzo de 1309, pocos meses antes, por tanto, de que Jaime II de Aragón y Fernando IV de Castilla comenzaran su fallida campaña contra el reino nazarí; por el contrario, ve en Llull a un influyente propagandista de los argumentos jaiminos en favor de dicha expedición: «Es evidente que este libro se escribió con el objetivo de presentarlo al papa Clemente $V$ para convencerlo de la necesidad de la acción bélica del rey aragonés» (p. LX).

\section{La edición y estudio del Liber de acquisitione Terrae Sanctae}

Conviene destacar que, además de la introducción general, cada una de las obras editadas en el volumen se acompaña de un estudio introductorio particular en el que se abordan cuestiones como la autenticidad del libro en cuestión, los elementos más destacables de su contenido o las circunstancias de su fortuna textual, con indicación de las relaciones existentes entre los testimonios conservados. De todas estas obras, la más extensa y también, quizá, de mayor entidad, debido a las circunstancias que rodearon a su composición, es el ya citado Liber de acquisitione Terrae Sanctae (op. 146; Montpellier, marzo de 1309). En los «Prolegomena» (pp. 159201) que preceden a la edición (pp. 205-229) se nos ofrece un análisis completo y preciso del sentido de la obra y de su posición dentro del corpus luliano dedicado a la reflexión y las propuestas sobre la cruzada. En efecto, Domínguez compara este opúsculo con otros de la misma temática, prestando especial atención a las semejanzas y divergencias que presenta con el Liber de fine (op. 122; Montpellier, abril de 1305). En primer lugar, señala que, aunque en el De acquisitione Llull justifica retomar el tema de la cruzada «propter casum Templariorum» («De prologo», p. 206), esto es, debido al nuevo escenario histórico planteado tras el arresto de los líderes del Temple por parte de Felipe IV de Francia (1307), lo cierto es que, si se compara la obra con el De fine, se constata que los cambios parecen tener poco que ver con el episodio al que alude el mallorquín; más bien, las diferencias se deben «a la desigual circunstancia y al concreto objetivo que perseguía Raimundo con uno y otro libro» (p. 160). Así, aunque en el De fine (que fue presentado al papa Clemente V en el curso de una entrevista que tuvo lugar en Montpellier entre el 7 y el 11 de octubre de 1305, y en la que se hallaban también presentes los reyes de Aragón y Mallorca) Llull contempla la vía militar como una solución posible para integrar al cristianismo los territorios habitados por los infieles (de hecho, la exposición de esta vía es presentada como la razón primera del tratado), se observa con bastante claridad su preferencia por la acción misional y la disputa intelectual utilizando los instrumentos de su Ars como métodos de conversión. En este último sentido, a juicio de Domínguez, el De fine, so pretexto de hablar de la cruzada, parece más bien una carta de presentación ante el papa de «la persona que escribe, sus libros, su método de conversión y las enormes ventajas de tal proyecto» (p. 166).

Por su parte, en el más breve De acquisitione encontramos una obra bastante alejada del discurso característico del Ars, en la que tiene una importancia preponderante la exposición de planes castrenses para convertir el Mediterráneo en un mare internum de la cristiandad, seguramente porque los príncipes y prelados que Llull tenía en mente al escribirla (estaba igualmente destinado a ser entregado al papa) no podían concebir la relación de la cristiandad con el Islam en otros términos que no fueran los de la confrontación armada (a este respecto, Domínguez, p. 162 y nota 8 , alude a la Vita coaetanea, $\$ 35$, en donde Lull se refiere a la displicencia con la que, durante la entrevista de 1305 , Clemente $\mathrm{V}$ y los cardenales acogieron su propuesta de creación de monasterios para la formación lingüística e intelectual de misioneros que, en el futuro, viajaran a tierras de infieles para predicarles en su lengua y convertirlos por la fuerza de la razón). Sea como fuere, las reflexiones de tipo estratégico recogidas en el De acquisitione permiten apreciar «la propia experiencia de un viajero con un conocimiento poco común del escenario mediterráneo» (p. 161). Su visión de una cruzada universal que, partiendo del sur de España, siga el itinerario norteafricano parece fuertemente influenciada por los que en el momento de la composición de la obra eran los principales intereses de Aragón en materia de política exterior (de hecho, para Domínguez en el libro Llull ejerce como una suerte de «portavoz ante el papa de los planes de guerra contra los infieles propuestos por Jaime II de Aragón», p. 166), y concuerda igualmente con la visión de 
Luis IX de Francia, monarca que «pretendió encontrar a lo largo de la costa mediterránea africana un camino para llegar más rápido a Tierra Santa» (p. 163), y a quien Llull se refiere elogiosamente en varias de sus obras.

Cabe señalar, a este mismo respecto, que el modo en que Llull justifica las bondades de la ruta berberisca concuerda también con la visión de un contemporáneo suyo como Ramón Muntaner: en efecto, si, como explica Domínguez, para Llull «en África podía avanzar el cristianismo con mucha más rapidez dado el carácter desértico de los interiores. Dominando la costa se dominaban también los caminos del mar» («Introducción general», p. LXVI), en la Crònica muntaneriana se puede leer un argumento geográfico semejante al referirse el cronista al supuesto proyecto de Pedro III el Grande de someter la costa norteafricana y convertirla al cristianismo: «E la Barberia és aytal que qui haurà les marines, haurà tota Barberia; et són gents qui tantost con vejen lo gran destret que hauran, se faran crestians la major part» ${ }^{1}$.

Domínguez sigue desgranando las diferencias entre el De fine y el De acquisitione al analizar la estructura de este último, dividido en tres distinctiones, a saber: I. De modo bellandi; II. De modo praedicandi; III. De exemplis. En la distinctio I se concentran todas las cuestiones relativas a los criterios militares y la estrategia a seguir para conquistar para la cristiandad las tierras ocupadas por los infieles. Se subdivide a su vez en cuatro secciones:

I.1. Enumeración de las ventajas que los cristianos poseen sobre los sarracenos en lo que a tecnología militar se refiere (De auantagio quod habent Chistiani contra Saracenos cum armis, p. 208). Se listan seis aspectos en los que se manifiesta la superioridad del armamento cristiano (frente a las doce ventajas, nota Domínguez, p. 170, de las que se habla en el De fine): galeras, ballestas, lanzas, armas defensivas, infantería ligera y maquinaria de asedio. El editor compara estas observaciones con las que pueden leerse en las obras de otros teóricos de la cruzada (Marino Sanudo, Pierre Dubois, Fidenzio de Padua), y concluye-acertadamente, creemos- que, si bien no llegan al nivel de precisión de los autores mencionados, sí que muestran a un Llull «bien enterado de las técnicas de combate» de su tiempo (ps. 170-171).

I.2. El papel de Constantinopla en la cruzada. Llull defiende la colaboración entre Bizancio y Roma, previo sometimiento de la primera a la obediencia religiosa de la segunda. También sugiere que, de ser necesario, la reintegración de Constantinopla al catolicismo romano puede lograrse por las armas, afirmación que debe entenderse como una captatio benevolentiae del papa, en quien el beato pensaba como lector del libro, pues es sabido que Clemente V favorecía abiertamente los proyectos de una expedición contra Constantinopla para reinstaurar el Imperio Latino trazados por Carlos de Valois con el apoyo del maestre hospitalario Fulco de Villaret. De hecho, Llull cita a ambos personajes como los líderes llamados a llevar a cabo tal empresa. En este sentido, Domínguez (p. LXVIII de la «Introducción general»), señala una nueva y significativa divergencia con respecto al De fine, en donde Llull había desaconsejado la ruta constantinopolitana por ser poco efectiva para la consecución de los objetivos de la cruzada.

I.3. La vía norteafricana como posible itinerario de la cruzada. A pesar de todo, parece clara la preferencia de Llull por la ruta de África como mejor estrategia a largo plazo. Antes, sin embargo, de proceder a la invasión de las costas berberiscas es necesario reconquistar para la cristiandad el reino de Granada, para lograr lo cual, según Llull, es condición indispensable la estrecha cooperación entre los reges quattuor nobiles, qui sunt uersus partes occidentales (p. 212), pasaje que Domínguez interpreta como una alusión a los monarcas peninsulares de la época (Aragón, Castilla, Portugal y Navarra), apreciación muy razonable si se tiene en cuenta que el propio Llull se refiere un poco más adelante (p. 214) a la célebre batalla de las Navas de Tolosa, en la que las fuerzas combinadas de los reinos hispánicos derrotaron al ejército invasor almohade, y que, de hecho, las apelaciones a la unidad de acción de los diferentes «reyes de España» son frecuentes en los textos de los siglos medievales: así, por ejemplo, el trovador Pèire Vidal (siglos XII-XIII) lamenta en su poema Plus que.l paubres, quan jai el ric ostal la desunión de los reinos cristianos peninsulares e imagina una gran coalición ibérica per hacer frente

1 Muntaner, R., La Crònica de Ramon Muntaner: edició i estudi (Pròleg - capítol 146), a cargo de J.A. Aguilar, Barcelona, Institut d'Estudis Catalans, vol. II, p. 287. 
al infiel: «Als quatre reis d'Espanh'esta mout mal, / quar no volon aver patz entre lor! / quar autramen son ilh de gran valor, / adreit e franc e cortes e leyal, / sol que d'aitan gensesson lur escuelh, / que viresson lor guerr'en autre fuelh, / contra la gen que nostra lei no cre, / tro qu'Espanha fos tota d'una fe» ${ }^{2}$; y Muntaner señala en un punto de su Crònica que «si aquests IIII reys [...] d'Espanya, qui són una carn et I sanch, se tenguessen ensemps, poch dubtaren et preharen tot l'altre poder del món» ${ }^{3}$. Conquistada Granada, el papa deberá financiar a los ya mencionados reges quattuor para que estos emprendan la toma de Ceuta, que deberá ser repoblada y fortificada para convertirse en la cabeza de puente de la expansión cristiana por el norte de África. Domínguez observa que la descripción de las fortificaciones que habrán de erigirse en torno a la ciudad es tan detallada que «es obligado pensar que Raimundo conocía el puerto de Ceuta y sus aledaños» (p. 180), aunque apunta también la posibilidad de que Llull hubiera sido informado de estos detalles por el entorno del propio Jaime II, interesado en vehicular su visión acerca de la cruzada quedase plasmada en el memorial luliano que había de ser presentado a Clemente V. Parece esta una hipótesis plausible, porque en algún punto del De acquisitione se señalan aspectos estratégicos que aparecen frecuentemente en las instrucciones que Jaime entregaba a los diplomáticos encargados de llevar a cabo alguna embajada ante el papa: por ejemplo, si Llull apunta que, para poder conquistar Granada será necesario que una escuadra de galeras cristianas mantenga bloqueado el paso del Estrecho, a fin de que el reino nazarí no pueda recibir refuerzos procedentes de la Berbería («quod teneatur passus cum galeis munitus, ita quod rex Granatae non possit habere subsidium neque adiutorium ab aliis Sarracenis», p. 212), los memoriales de la diplomacia aragonesa durante el reinado de Jaime II solían insistir precisamente en este mismo punto («ut dictum mare strictum (...) per Christianos cum galeis custodiretur») ${ }^{4}$.

I.4. El concepto de guerra continua (bellum perpetuum) contra los infieles. Esta lucha, según Llull deberá ser llevada por un magister generalis a cargo de todos los contingentes destinados a la cruzada, que deberá comprometerse a permanecer en todo momento en la frontera contra los infieles. Se trata de un aspecto que Llull ya aborda en el De fine, aunque en esta obra, como apunta Domínguez, el término utilizado para referirse a este capitán general es el de rex bellator.

Una vez tratadas las armas materiales con las que se deberá llevar a cabo la cruzada, en la distinctio II (De modo praedicandi) Llull habla de las armas espirituales, esto es, de los medios intelectuales necesarios para explicar a los infieles los dogmas de la fe cristiana y convencerles de la superioridad de esta. Se subdivide en seis partes:

II.1. Fundación de monasterios para la formación intelectual de misioneros. De acuerdo con una idea presente en buena parte de su producción escrita, Llull propone aquí la creación de centros que sigan la estela del modelo ensayado en Miramar, en los que los futuros misioneros puedan formarse en lenguas como el árabe, el griego o el tártaro, para poder predicar y disputar con los infieles en su idioma. Naturalmente, la idea clave aquí es que se espera del papado que sufrague la puesta en marcha de estos monasterios; Llull sugiere incluso que el pontífice debería designar uno o dos cardenales exclusivamente dedicados a esta cuestión (p. 217).

En las cinco partes subsiguientes, Llull habla de los diferentes métodos que los misioneros deberán emplear para disputar con los infieles según las creencias de estos:

II.2. Musulmanes. Llull considera prioritario instruir y tratar de convertir en primer lugar a los musulmanes instruidos en materias como la filosofia; Domínguez explica muy bien las razones que subyacen a esta recomendación: «Lulio, en el fondo, advierte de un hecho evidente y optimista, la existencia en cualquier comunidad humana de personas críticas, curiosas y activamente receptivas de la verdad sapiencial con las que se puede discutir racionalmente y demostrar la fe en base a una común cognitio naturalis» (p. 185). De hecho, Llull señala que los musulmanes están más cerca de Dios que otros pueblos infieles porque el Corán aprecia la

2 Vidal, P., Poesie, a cargo de D’Arco Silvio Avalle, Milano, Ricciardi, 1960, vol. I, p. 325.

3 Muntaner, R., La Crònica de Ramon Muntaner, op. cit., vol. II, p. 553.

4 Finke, H., Acta Aragonensia, Berlín - Leipzig, Rothschild, vol. I, p. CLXIX. Sobre las acciones navales en el Estrecho, véase también Dufourcq, C.E., L'expansió catalana a la Mediterrània Occidental : segles XIII $i$ XIV, Barcelona, Vicens Vives, 1969, passim. 
figura de Jesús. Por tanto, para traerlos a la verdadera fe, serán precisos misioneros que sepan demostrar por medio de rationes necessariae los dogmas de la Trinidad y la Encarnación.

II.3. Judíos. Llull no los considera un pueblo capacitado para la disputa per rationes necessarias. Domínguez expone así el punto de partida de esta visión luliana: «La primera consideración que hace Lulio sobre las disputas con los judíos es el hecho de que su ciencia no es racional y solo discuten sobre y con el libro sagrado» (p. 189). Es cierto, señala Llull, que los judíos comparten libro con los cristianos, pero lo interpretan de modo diferente, por lo que una disputa per auctoritates con ellos no sería fructífera: esta no se produciría en términos racionales y ambos contendientes se limitarían a contraponer las diferentes interpretaciones del texto bíblico. La solución propuesta por el beato es que el papa debería obligar a los judíos a aprender latín o una lengua vulgar para poder discutir con ellos racionalmente.

II.4. Herejes. Llull los presenta como gente inculta que se cree inteligente, desprovista de sapientia, potestas ni caritas (tres conceptos procedentes del Arte Grande que, como destaca Domínguez, pp. 167-168, tienen gran importancia en el desarrollo del De acquisitione). Sus herejías pueden ser rebatidas fácilmente mediante rationes basadas en las tres virtudes mencionadas.

II.5. Cismáticos. Se incluyen en esta categoría griegos, nestorianos, jacobinos o monofisitas. Para Domínguez (p. 191), que concuerda en este punto con Viola Tenge ${ }^{5}$, la visión que tiene Llull sobre estas comunidades es más bien limitada y superficial.

II.6. Tártaros. Se trata a ojos de Llull de gente ruda y sin religión, con la que se puede disputar recurriendo a cuestiones morales planteadas según los términos plasmados en el Arte Grande. Para evitar la posibilidad de que adopten una religión como el Islam, será necesario que se les muestre no sólo la verdad de la fe cristiana, sino también la falsedad de todas las demás, lo que según Llull se puede conseguir siguiendo algunas obras suyas como el Liber de gentilis et de tribus sapientibus (op. 11) o el Liber disputationis Raimundi christiani et Homeri saraceni (op. 131).

Este punto enlaza con la distinctio III (De exemplis), en la que Llull se refiere a los peligros que acechan a la Iglesia si hace caso omiso de las propuestas por él formuladas. Entre estos peligros, insiste de modo especial en el de una posible conversión al Islam de los tártaros, que acarrearía graves consecuencias para toda la cristiandad. Desde el punto de vista de la reflexión etnológica, resultan interesantes, como remarca Domínguez, las razones que, según el De acquisitione, podrían contribuir a este proceso de islamización: «No deja de ser aguda la observación que hace Lulio sobre la vida intelectual de los tártaros como pueblo nómada. La vida no sedentaria de los mongoles les impide tener centros de formación intelectual, por eso buscan y encuentran ellos entre los musulmanes gente docta y erudita que les ayuda en tareas de educación y escritura» (p. 196). Por este motivo, Llull incide en la importancia de enviar misioneros cristianos capacitados para frenar y contrarestar este fenómeno. Sobre este punto, conviene notar que los planteamientos lulianos pueden ser puestos en relación con una corriente de opinión que veía en los mongoles a un pueblo fácilmente convertible al cristianismo y, por tanto, a un posible aliado en la lucha contra el Islam, corriente que en las letras catalanas medievales cuenta con varios hitos destacados: así lo documenta Albert Hauf, que alude al tratamiento que la figura del emperador tártaro recibe en el Llibre dels fets de Jaime I o al hecho de que en los territorios de la antigua Corona de Aragón circulara, traducida al catalán y al aragonés, una obra como La flor de las historias de Oriente, del armenio Haitón de Córico (siglos XIII-XIV), en donde se aboga por una alianza cristiano-mongólica para la reconquista de Tierra Santa ${ }^{6}$.

5 Tenge-Wolf, V., «Lulls Auseinandersetzung mit den Ostkirchen in der Disputatio und in anderen Werken», en Raimundi Lulli Opera latina, vol. XXXV. Op. 54-60, annis 1294-1296 composita, a cargo de C. Colomba y V. Tenge-Wolf, Turnhout, Brepols (Corpus Chistianorum Continuatio Mediaevalis 248), 2014, pp. 225-232.

6 Véanse Haitón de Córico, La flor de les històries d'Orient (versió del segle XIV), a cargo de A. Hauf, Barcelona, Centre d'Estudis Medievals de Catalunya (Biblioteca Escriny, Col·lecció de Textos Medievals Breus, 9), 1989; Hauf, A., «Texto y contexto de La flor de las historias de Oriente: un programa de colaboración cristiano-mongólica», en A. 


\section{Cartas al rey de Aragón, a la Universidad de París y a la corte francesa}

En el volumen se publican también cuatro epístolas que dan buena prueba de las relaciones al más alto nivel que, dotado de un sentido práctico que le llevaba a buscar la ayuda de agentes de poder que pudiesen hacer avanzar su programa apologético, entabló Llull con algunos de los soberanos, prelados e instituciones más influyentes de la época. La primera de estas cartas (op. 142; p. 12), dada en Montpellier a 19 de febrero de 1309 , está dirigida a Jaime II de Aragón, con el que el mallorquín mantenía una cordial relación y a quien había servido como agente propagandístico con la redacción del De acquisitione. En ella, Llull le comunica el envío de un libro suyo llamado De proverbis, que acaba de componer, destinado a la educación de sus hijos, y cuya lectura los convertirá en príncipes sabios y justos. Sin embargo, como subraya Domínguez, el libro no parece ser el principal motivo de la redacción de la misiva, porque de la lectura de la misma se desprende que en realidad que lo que Llull le pide al rey es ayuda económica «supra negotiu quod iam scitis» (p. 12), lo que el investigador y editor interpreta como una alusión velada del beato a la misión que el rey de Aragón le había confiado de viajar a Aviñón para entrevistarse con Clemente $\mathrm{V}$ y hablar en favor del proyecto aragonés de una expedición contra Granada (p. 5). Por otra parte, Domínguez aborda la cuestión de qué obra puede ser el De proverbis del que se hace mención en la carta. En concreto, analiza si resulta plausible identificarla con los Proverbis d'ensenyament. Tras resumir el contenido de este último texto y las circunstancias de su transmisión textual, se inclina por considerar, en línea con lo apuntado por Francesc Tous ${ }^{7}$, que la identificación con el De proverbis no parece aceptable, puesto que de lo que Llull dice en su carta se deduce que este se trata más bien de un speculum principum dividido en varias rúbricas o capítulos, mientras que los Proverbis d'ensenyament son un conjunto de dísticos de contenido moral en el que no se aprecia rastro de ningún orden sistemático (pp. 22-24). Aclara, sin embargo, que con los datos de que actualmente disponemos no es posible «resolver el tema de una manera definitiva y categórica» (p. 24).

Las tres cartas restantes (op. 151-153; pp. 323-342), de fecha no especificada en el único testimonio manuscrito que de las mismas se conserva, están dirigidas a varios ilustres destinatarios del reino de Francia: la Universidad de París, el rey Felipe IV y un clérigo innominado de la corte real francesa. Lo que las une desde el punto de vista del contenido es la petición que Llull hace a los receptores para que se comprometan a fundar centros en los que los futuros misioneros puedan aplicarse al estudio de los idiomas «arabicum, tartaricum et graecum» (p. 333). Domínguez considera que «observando el estilo de las tres cartas hay que suponer que, sobre todo, la primera de ellas, dirigida a la Universidad, no fue escrita por Raimundo, sino encomendada a un redactor» (p. 324), apreciación en la que concuerda con autores como Hillgarth o Perarnau ${ }^{8}$.

La explicación racional de los dogmas de la fe

El volumen se completa con la edición y estudio de siete tratados teológico-filosóficos redactados por Llull entre los meses de marzo y abril de 1309. Son los siguientes: Liber de maiori agentia Dei (op. 143; pp. 31-67); Liber de conuenientia, quam habent fides et intellectus in obiecto (op. 144; pp. 69-131); De duodecim syllogismis concludentibus duos actus finales, unum intrinsecum, alium extrinsecum (op. 145; pp. 133-156); Liber de propriis et communibus actibus dininarum rationum (op. 147; pp. 231-257); Liber de potestate diuinarum rationum (op. 148; pp. 259-275); Liber de nominibus diuinarum personarum seu De trinitate permansiue in essentia Dei (op. 149; pp. 277-300); Liber de probatione, quod in Deo sunt tres personae (op. 150; pp. 301-320). Como explica Domínguez (p. 77), en ellos encontramos a un Llull que, tras haber asentado su teoría de las dignidades y justificado la validez universal de la estructura relativa, pretende desarrollar una

Egido y J.M. Enguita (eds.), Juan Fernández de Heredia y su época. IV Curso sobre Lengua y Literatura en Aragón, Zaragoza, Institución Fernando el Católico, 1996, pp. 111-154.

7 Tous, F., Les col-leccions de proverbis de Ramon Llull: estudi de conjunt i edició dels Mil proverbis $i$ dels Proverbis d'Ensenyament, Barcelona, Barcelona, Universidad de Barcelona, 2018 [tesis doctoral].

8 Hillgarth, J.N., Ramon Llull and Lullism in Fourteenth-Century France, Oxford, Oxford University Press, 1971, pp. 13 y 50, n. 12; Perarnau, J., «La còpia manuscrita medieval de les tres lletres de Ramon Llull demanant al rei, a un prelat de França i a l'estudi de París l'establiment d'escoles de llengües (Clarmont-Ferrand, BMI, ms. 96)», Arxiu de Textos Catalans Antics, 21 (2002), p. 208. 
silogística sólida puesta al servicio, naturalmente, de la demostración de las verdades de la fe, entre ellas los dogmas de la Trinidad y la Encarnación. Así, por ejemplo, el Liber de conuenientia se centra en demostrar la absoluta armonía existente entre creer (fides) y entender (intellectus), un hecho que implica no sólo la posibilidad, sino la obligación que todo intelectual cristiano tiene de probar racionalmente los fundamentos del credo cristiano. Domínguez (pp. 77-83) observa que se trata de un texto que conecta en muchos aspectos con la epístola que cierra el Liber de experientia realitatis Artis ipsius generalis (op. 138), en donde Llull afirma que los teólogos cristianos que defienden la imposibilidad de demostrar racionalmente los artículos de la fe lo hacen porque utilizan únicamente dos formas aristotélicas de demostración, per quia y propter quid, frente a lo cual el sabio mallorquín propone dos tipos de argumentos alternativos, la demonstratio per aequiparantiam y la demonstratio per hypothesim, que son precisamente empleados en la redacción del Liber de conuenientia. Merece destacarse el riguroso trabajo llevado a cabo por Domínguez para la fijación del texto de esta obra, caracterizada desde el punto de vista ecdótico por una transmisión ciertamente compleja, conformada no sólo por una traditio directa de 36 manuscritos además de la edición moguntina de 1729, sino también por una traditio indirecta que no puede ser obviada, pues las partes I y II de la obra se reproducen literalmente en la Sententia definitiva sobre la ortodoxia luliana de 1419, obra reimpresa en multitud de ocasiones entre los siglos XVI-XVIII (a estudiar este fenómeno se dedican las pp. 95-105 del volumen).

Cada una de las obras editadas se acompaña de un aparato crítico dispuesto en dos niveles: en el primer nivel, se anotan los aspectos culturales más significativos del texto; en el segundo, se consignan las variantes transmitidas por la tradición manuscrita e impresa del mismo. Además, al final del volumen se incorporan índices (de citas bíblicas, de nombres y de títulos) que facilitan al lector la localización y consulta de los contenidos. Estamos, en definitiva, ante una obra que aúna rigor filológico y un profundo conocimiento de la materia abordada para ofrecernos, amén de unos textos pulcramente editados, las necesarias claves para entender las circunstancias de su composición y el mensaje que el autor quería transmitir con ellos. Sin duda, se trata de una muy valiosa adición al campo de los estudios lulianos.

JOSEP ANTONI AGUILAR ÁVILA

Universidad Católica de Valencia

\section{JOSÉ HIGUERA RUBIO, Física y teología (Atomismo y movimiento en el Arte luliano). Madrid, Círculo Rojo, 2014, 326 pp., ISBN: 9788490508190}

Queremos acercarnos aquí, en esta breve nota o recensión bibliográfica, a una, o mejor, dos piezas de interés en el marco de la galaxia luliana. Responden, por así decir, a trabajos preparatorios del Any Llull (2017) (700 aniversario de la muerte de R. Llull, uno de los pilares de la filosofía hispana), de emotivo recuerdo, que se ha celebrado en Baleares, Cataluña, incluso en Galicia, el Estado Español, Europa, Iberoamérica y América del Norte, con numerosos actos académicos, propuestas de investigación y monografías.

El profesor José Higuera Rubio no es precisamente un desconocido en el mundo del lulismo. Colaborador del Departamento de Filosofía III (Universidad Complutense de Madrid), donde imparte seminarios sobre las formas de transmisión de la tradición filosófica medieval, y del Institut d'Estudis Medievals (IEM) adscrito a la Universitat Autònoma de Barcelona (dirigido José Enrique Ruiz-Domènec y Alexander Fidora), al que está estrechamente ligada la monografía que citamos en segundo lugar. Es figura relevante en los medios académicos internacionales, en su vertiente investigadora, tanto en relación con la historia de la filosofía medieval como con el lulismo. Sobra decir que, en este último campo, ha llevado a cabo una empresa titánica: la fundación, junto con otros, pero con protagonismo propio, en 1999, del Instituto Brasileiro Raimundo Lúlio (São Paulo, Brasil) (IBFCRL), interconectado desde entonces con el mencionado IEM, con el Raimundus-Lullus-Institut de la Universidad de Friburgo, en el que ha desempeñado un papel editorial muy importante en los últimos años 